\title{
FOREWORD
}

\section{Cynthia Larson}

A number of new developments make this issue of the $U L S$ a unique one in the journal's seven year history. The first recent development of note is that the editor of the $J L S$ for the past six years, Kathleen Welch, 'resigned' in favor of accepting a tenure-track job at the University of Oklahoma. From Kathleen and her editors, Brady Earnhart and Beth Nugent, the current staff inherited the work accepted for publication in 1981-82. Thus the choice of material for this issue divides rather neatly between two separate editorial staffs, with the former staff earning the praise for the poetry, fiction, and interviews, and the new staff adding their selections of criticism and book reviews, editing one interview, and accepting the seemingly endless jobsfrom cover design to proofreading to financing to final distribution and publicity-involved in any publishing venture.

Another development new with this issue is our leap into the computer age. The $J L S$ now has its own computer program which should mean a cheaper, easier, and faster production process. We hope with this change that two issues per year become reality rather than dream.

The ULS is a journal managed and edited by graduate students who are interested in steering some fine University of Iowa graduate student work into print. We aim to provide a place where graduate students can find the work being done by peers in such diverse departments as, for example, English or Broadcasting, American Studies or Art, the Writer's Workshop or History, and so foster a healthy and stimulating exchange of ideas. We hope as well to encourage the kind of professionalism expected by academic journals.

If you are a graduate student at the University of Iowa (or a recent graduate), the staff of the ULS invites you to submit articles, essays, book reviews, fiction, poetry, interviews, and art work to be considered for publication. Please consult the MLA Style Sheet in the preparation of manuscripts. TWO CLEAN copies, preferably not much longer than fifteen to twenty pages, 
should be sent via campus mail to Iowa Journal of Literary Studies, Department of English, 308 EPB. If submitting poetry, please send no more than six poems. Please include a RETURN CAMPUS ADDRESS with your submission. All submissions are reviewed anonymously, and all work published is copyrighted by the University of Iowa.

We hope you accept our invitation, and we hope you enjoy this issue. 
